Rupkatha Journal on Interdisciplinary Studies in Humanities (ISSN 0975-2935), Vol. 10, No. 1, 2018 Special Issue on "Interrogating Cultural Translation: Literature and Fine Arts in Translation and Adaptation" In collaboration with the Department of English, Amrita Vishwa Vidyapeetham Guest-edited by Dr. Hari M G, Amrita Vishwa Vidyapeetham, Coimbatore, India

DOI: https://dx.doi.org/10.21659/rupkatha.v10n1.02

Full Text: http://rupkatha.com/V10/n1/v10n102.pdf

\title{
Literature (Now) Contains Graphic Language: Adaptation, Visualization and Transmedia Texts
}

\author{
Pramod K. Nayar \\ Professor, Department of English, University of Hyderabad, India. \\ ORCID: oooo-ooo3-2317-6570. Email: pramodknayar@gmail.com
}

Received December 15, 2017; Revised January 26, 2018; Accepted January 30, 2018; Published February 04, 2018.

\begin{abstract}
Literary influence is now visible in the form of a graphic visualization, whether as a graphic novel or, as this essay demonstrates in computer-generated visual data around texts and textual relations. All of these are adaptations of the literary text. I first argue that the 'graphing' of the source/original - if we retain oldworld categories such as 'original' - text into visual language renders literary texts into our most recognizable interface: the screen with its icons. This iconization in graphic adaptation is a mirroring and a ghostification. In the second part of the essay I argue that textual criticism is an instance of adaptation because the critical texts are produced from and about literary texts. Today, this process utilizes the graphic language and representational modes of the digital medium and is therefore transmedial. Maps of literary influence, built through software, graphic visualizations of literary texts. In the third section, the essay argues that the work of criticism in the digital age gestures at the contexts and processes outside the task and textual frame, and to signs and symbols within it. In transmedia metareferencing is a form of adaptation because it takes material from various media to compose the cultural history of the text in the form of whatever is laid out on the screen. In the final section, the essay proposes a poetics of transmedia adaptation and graphic visualization.
\end{abstract}

Keywords: Graphic Language, transmedia adaptation, graphic visualization, metareferencing, graphic language.

When literature, as in contemporary adaptations of canonical literary texts, turns graphic, it instantiates a feature of intertextuality. The source text may or may not remain consistent across the adaptations, but the undefinable and unquantifiable feature of the process is that vague category called literary influence. I propose that adaptation is primarily an instantiation of literary influence embodied in the form of intertextuality. Whether this is the repurposing of canonical Carroll by Beddor, Jane Austen for zombie fiction or the appropriation of modernist aesthetics from Ezra Pound's Cantos in Dakota (as has been argued by Jessica Pressman in Digital Modernism), we are speaking of literary influences.

(C) AesthetixMS 2018. This Open Access article is published under a Creative Commons Attribution Non-Commercial 4.0 International License (http://creativecommons.org/licenses/by-nc/4.0/), which permits non-commercial re-use, distribution, and reproduction in any medium, provided the original work is properly cited. For citation use the DOI. For commercial re-use, please contact editor@rupkatha.com. 


\section{Figure 1}

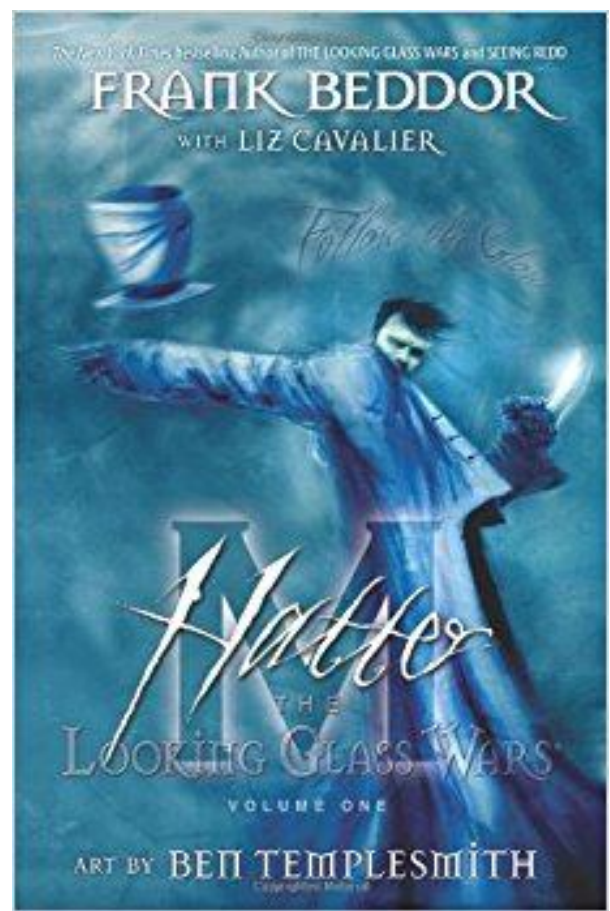

Beddor's Hatter

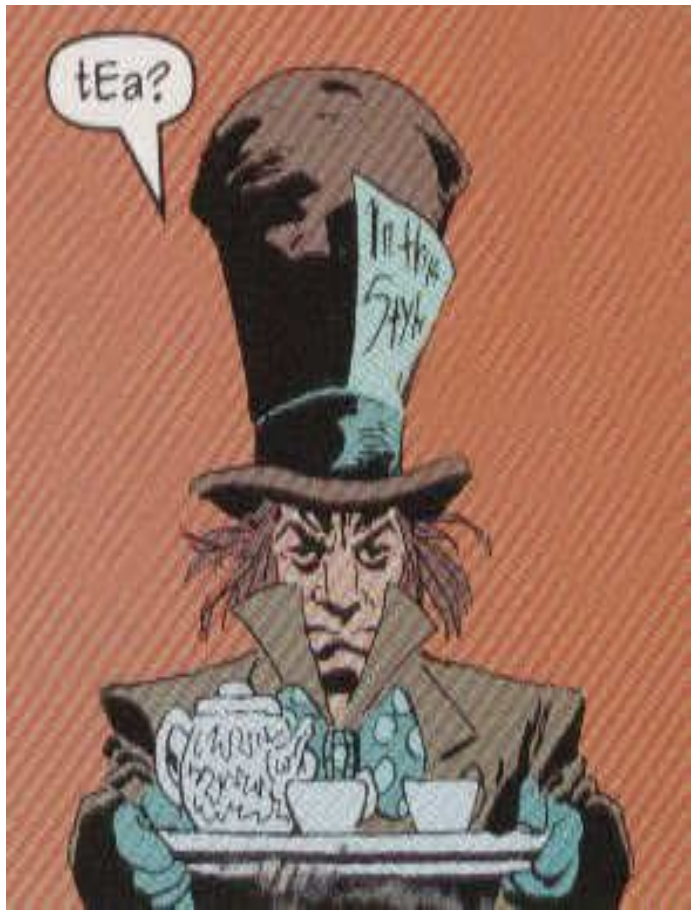

Hatter in Batman, The Long Halloween

Figure 2 Video, Young-hae Chang, Dakota

For the actual video visit www.yhchang.com/DAKOTA.html

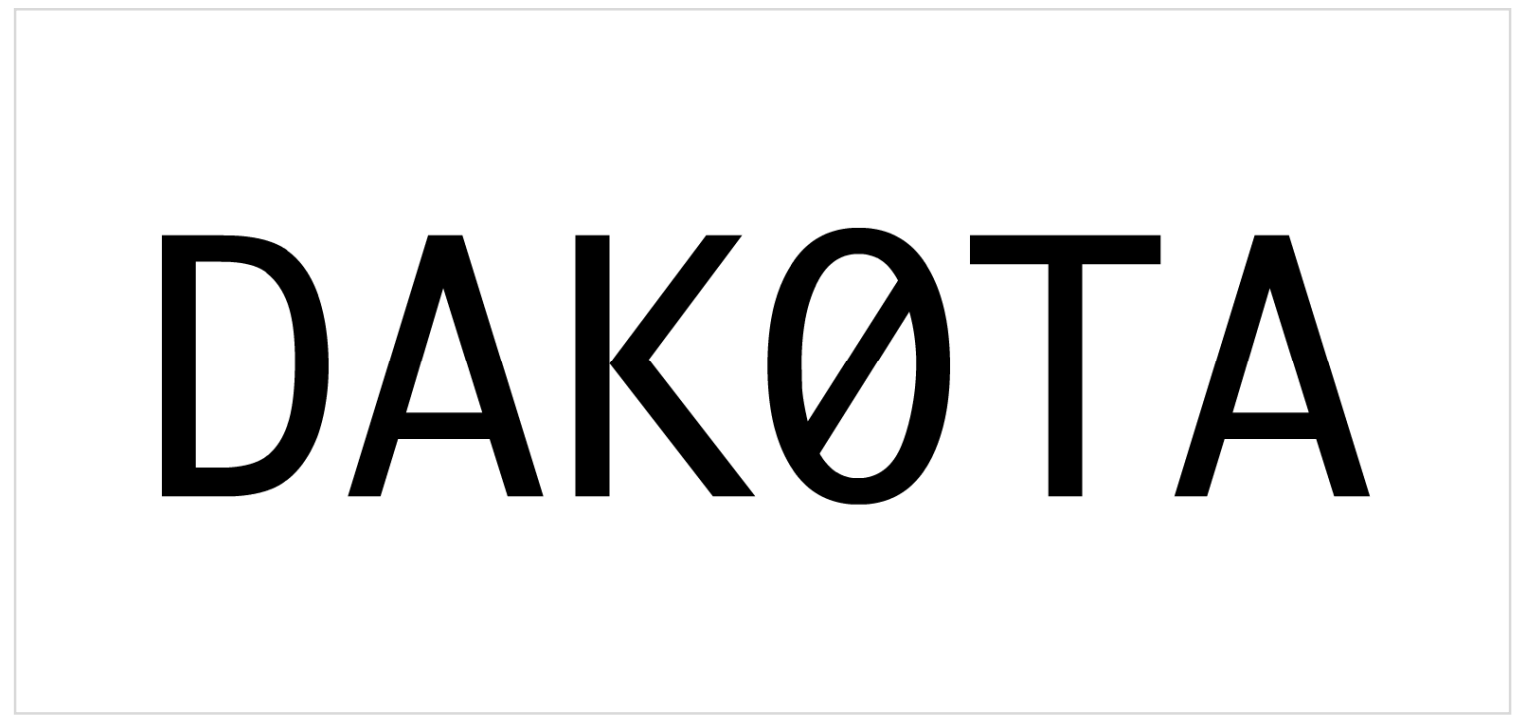

Adaptation of literary texts for different audiences demands an intertextualization and multimodalization. Carroll's Through the Looking Glass, perhaps, is a classic instance of this multimodalization where a literary text, when illustrated by John Tenniel, becomes as famous for the hideous creatures and oddities in the visual form as the frightening near-Gothic text of the Alice story. When Frank Beddor repurposes, with Liz Chevalier and Ben Templesmith in The 
Looking Glass Wars, the Alice-story, the Hatter is the hero of the tale. In fact, Alice, now Alyss, is missing through the better part of the 5-volume saga. Hatter is a warrior now, seeking the missing Princess of Wonderland, Alyss. The story unfolds over multiple locations, from the Far East to the American civil war, England to Europe, each volume progressively more violent than the preceding one. In Batman: The Long Halloween and other texts, Jervis Tetch is one of the prime villains.

I use the term 'graphic' to gesture at multiple variants of the graphological impulse: graphic novel adaptations, the addition of graphic language to canonical texts and of course in the digital medium when literary texts flashing on screen are bounded but also altered in terms of their syntagm, by other visual cues.

The use of visualization of data, including those from literary texts in the form of, say, quantitative analysis has been the subject of considerable interest in the Digital Humanities. Traditional modes of analysis are disrupted, and new questions asked, with the arrival of computational and visualization tools. A summary of the changes in criticism in the Digital Humanities is available in Elyse Graham's introduction to a special issue of English Studies:

How do literary keywords such as style, influence and genre demand rethinking in the context of quantitative analysis? Do we necessarily abandon a theoretical commitment to foregrounding the material basis of texts when we use digital methods of "distant reading" to understand textual transmission? What is the relationship in literary studies-which continues to give a special place, in catalogues, syllabi, anthologies and indeed literary databases, to the individual author and the mythos of genius-between data and the data point? In English Studies, a field defined by its attention to verbal phenomena, how can visual tools and practices rework, rather than simply refigure, verbal information? How can the distinctive textures of experience that humanistic documents-such as poems, plays or letters-record complicate the codes, frameworks and methods of visualisation techniques that arose in the context of business and the sciences? Will the imbrication of digital methods into established humanities disciplines affect their social paradigms? When we use visual graphics to translate numerical data, what do we lose by privileging visual over other means of encoding information? (2017: 1)

Importing scientific practices, such as data-modelling, from the sciences, reinvents the humanities and reading practices. As Pawlicka points out about the 'new' humanities: 'once used primarily for written text, "reading" now refers just as readily to "data", "algorithms" and "patterns". These different objects of reading require different methods of reading, all dependent on quantitative literacy' (2017: 536).

\section{Graphic Adaptations as Iconization}

I borrow - adapt - here Linda Hutcheon's key suggestion that if we see adaptation as process ( 'extensive, particular transcoding) and as a process (as creative reinterpretation and palimpsestic intertextuality)', we can examine the reader/audience's modes of engagement with the text at hand - from the imaginative (in the case of printed texts) to aural and visual perception and the participatory (the video games around, say, The Hunger Games). Graphic adaptation, I suggest, is the modification of visual and cultural literacy because we are forced to read in new ways, the old texts. 
Further, the graphing of the source text into visual language also renders literary texts into the most recognizable interface we now know: the screen with its icons. But I have something else to say about this. Graphing involves iconization of texts (even granting that texts are themselves the carving out of characters - from kharax, to cut with an axe). 'Icon', etymologically, means a variety of related things: image, figure, picture, also statue from the Late Latin icon, from Greek eikon, likeness, image, portrait; image in a mirror; a semblance, phantom image; in philosophy, an image in the mind, related to eikenai be like, look like. Thus, while there is a clear visual meaning of the word there is also the suggestion of something intangible, like a mirror or a phantom image.

I suggest that iconization in graphic adaptation is a mirroring and a ghostification. First, it allows the artist to put a face on a set of qualities and characteristics that have been thus far described in words. That is, the printed qualities of a protagonist now acquire a physiognomy that serves as a mirror image of the words and the qualities. Further, this mirroring is ghostly because while the visualized image, the icon, is derived from the printed character (like ghosts are derived from the persons), they need not be the exact same versions. The icon re-animates, brings to (ghostly) life, the characters in the form of physiognomy or expressions, but there is no way we can ascertain that this is precisely the expression the character might have worn in the printed book. The icon could very well lead a new life, different from the life we have known of the character from the book we read. Thus Hatter as warrior or as villain substantially alters Carroll's Hatter.

Graphic renderings of printed characters, while mirroring them, need not be 'true' to them. Thus, our standard complaint that the film version did not do justice to the book simply means that a re-animated character is a mirror image and a ghost, but neither of this makes it the exact equivalent of the written portrait. The iconization draws out the visual from the printed, where the printed is the crypt from which the ghost emerges. Iconization in graphic adaptation is a cryptonymy, which problematizes the meaning of signs. Cryptonymy, a term derived from the work of Nicolas Abraham and Maria Torok, refers to the psychoanalytic concept of transgenerational haunting, a form of family narrative in which 'what haunts are not the dead, but the gaps left within us by the secrets of others' (Abraham and Torok 1987: 387). I propose that the printed text gives up its secrets through the iconization. These secrets would be secrets about what the characters looked like: how did their facial muscles change when they smiled or grimaced? What expressions did they wear when sad or thoughtful? That is, when Carroll's Hatter acquires these new faces and features in Hatter and the Batman comics, it gestures not only at the crypt, the secret, at the heart of the name in Carroll, but also toward the absence at the heart of the printed text which gives itself to multiple palimpsestic reanimations in a different medium. The printed language has an absence at its heart - but absence here is potential, and this potential manifests in the form of newer visualizations of the same character. The graphic icon gives a face to a printed name precisely because the printed name does not restrict the appropriation into another language and another medium. One could go so far as to say that at the heart of the printed, 'original' text is the unthought and the non-presence which is then thought up, or animated, in the form of the mirror- or graphic presence in comic books. The ghost or mirrorimage adds something to the original that enables us to read the new text differently.

Further, the icon of the character from the printed work appearing now in the new medium is an interface. It is an interface between the reader and the printed text, if s/he knows the printed text. That is, the icon in the graphic text Hatter is an interface I use to enter the Carroll world too. Exactly as the icon on the screen enables us, at a click, to enter another world, the icon of the graphic text enables us to return to the Carroll world that we know from the printed version. 
I would also like to forward here the idea, expanding the argument already made, that literary adaptation into graphic and visual media forms is a kind of transgenerational haunting for a very different set of reasons. It questions the status quo of older texts by prying them open for the contemporary. For a generation attuned primarily to the visual due to the dominance of the screen, these adaptations fit into an aesthetic and a cultural form of iconicity.

\section{Graphic Visualization in Textual Criticism as Adaptation}

Textual criticism has for a long time been concerned with allusions, echoes, resonances, borrowings and adaptations of texts. With digital culture a whole new mode of studying these has opened up. I propose here that textual criticism is itself an exercise in adaptation in terms of the critical texts produced about literary texts. This criticism partakes of the graphic language and representational modes of the digital medium and may justly be termed transmedial.

Contemporary digital culture studies, especially textual mapping projects such as Tesserae (U of Buffalo), have sought to pin down such influences by tracking the use of words and phrases. The web tool flags 'whenever a sentence in the target text shares two or more words (regardless of inflection) with a sentence in the source text' (Gawley and Diddams 2017). The authors examined included Horace, Livy, Ovid, Propertius, Tibullus, and Vergil.

With digital text-analysis tools, it has become possible to actually track literary influence (and plagiarism), in terms of passages, words, similes and metaphors. I suggest that the map of literary influence is itself a graphic visualization of literary texts.

Figure 3

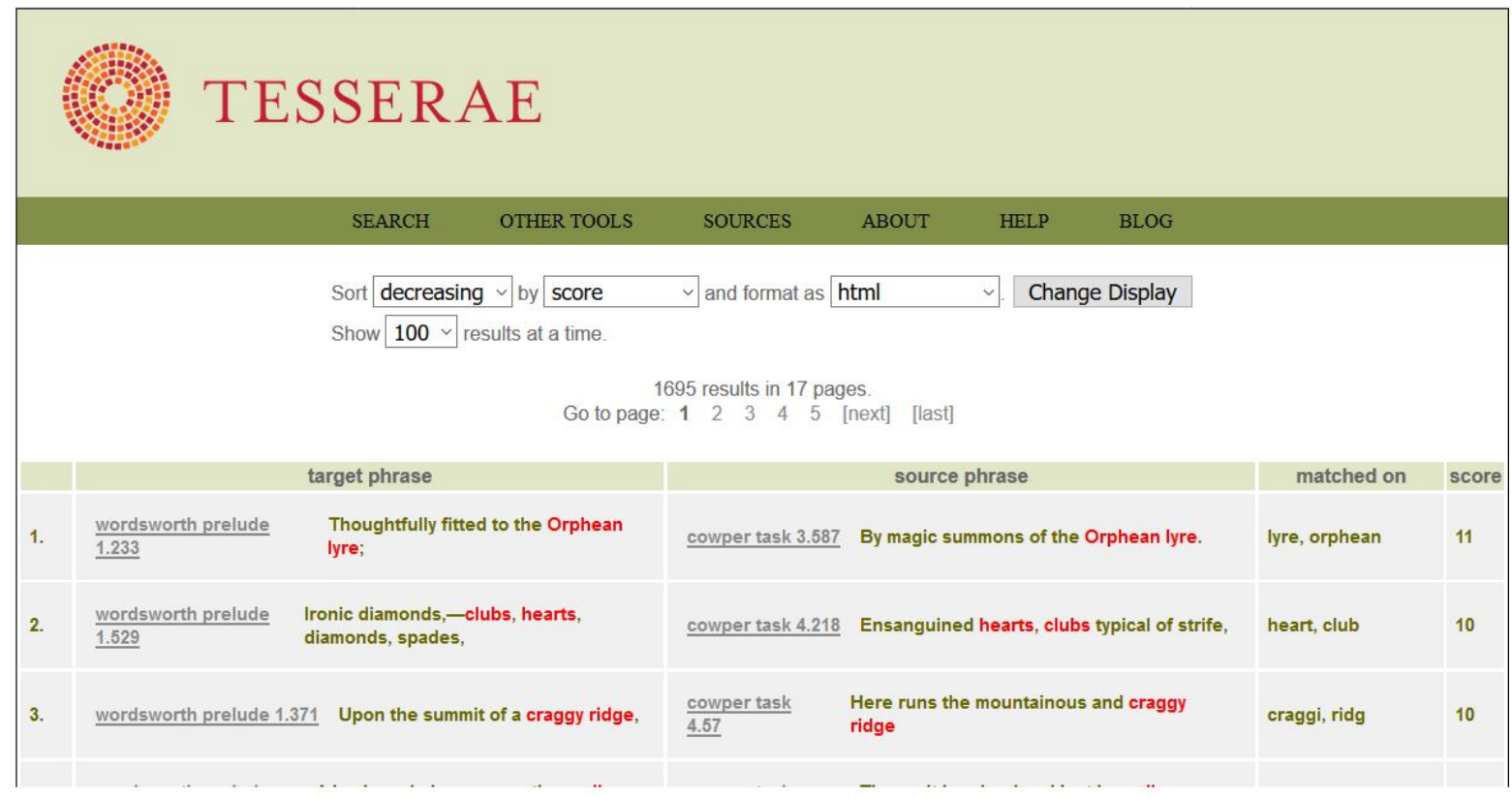

Tesserae

Now, Cowper and Wordsworth may or may not have been mutually influential, but if this were indeed the case then this influence itself is embodied in the map of intertextuality that we see here. It is my contention that such a map of intertextuality is also a graphing of the literary in a medium that forces us to read these canonical authors in certain ways. The visual 
Then, there is the visualization comparing variants. In textual criticism, the various versions of a Wordsworth poem built as footnotes or in a Variorum edition may now be displayed side by side to. Comparing the German translations of Shakespeare or the various translations of the Bible by tracking according patterns, synonymity, or transposed words, are now possible through software such as TRAViz. In many cases the actual flow of verse lines across editions or translations have been tracked as well. Visual patterns of textual similarity work in interesting ways, and not just to students of book/textual history. Tracking words and grouping them into visual patterns (see, for instance, TextArc) can also enable 'more abstract representations of textual attributes' (Sinclair and Rockwell 2016: 286).

Critics have noted that when we engage in such an analysis, we become aware of the imperatives of an editor or redactor in the past. For instance, they have noted how The Romance of the Rose and other medieval romances were redacted in order to have a greater ease for oral performance rather than reading. This suggests adaptation, trackable through the software, but the visual display itself is an adaptation.

\section{Figure 4}

show the variations between different editions of texts. IRAVIz supports the collation task by providing methods to:

- align various editions of a text

- visualize the alignment

- improve the readability for Text Variant Graphs compared to other approaches

- interact with the graph to discover how individual editions disseminate

\section{An Example: Genesis 1:1}

The following example demonstrates the basic idea of TRAViz. Various English translations of the Bible exist, each one was written with a specific intention. The spellings and chosen terms differ among these editions. Enclosed, we list seven translations of the first Bible verse - Genesis 1:1:

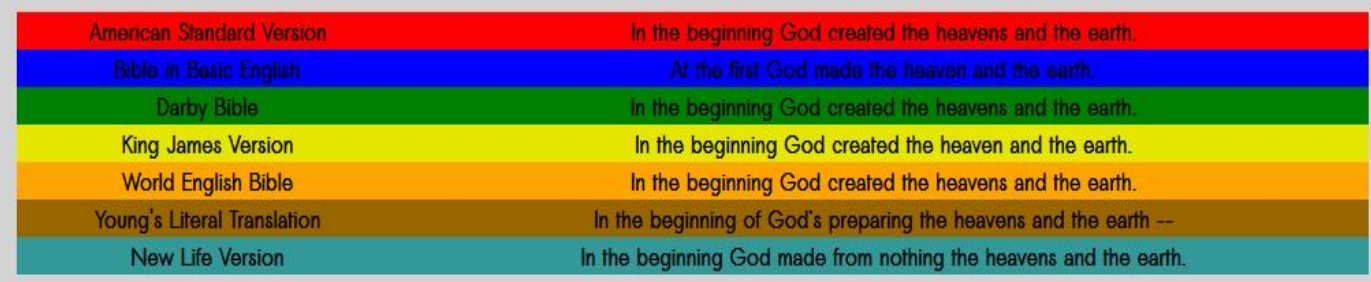

TRAViz can be utilized to compute the alignment between these various editions of Genesis 1:1 and to visualize the resultant Text Variant Graph. Now, one is able to explore the similarities and differences among the given editions easily.

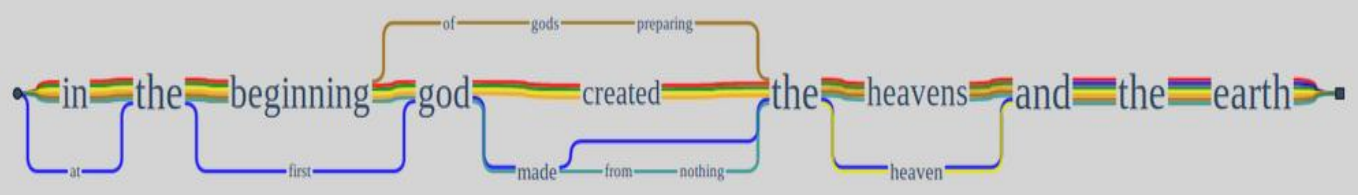

Thanks!

For the support of friends and family and fruifful discussions with colleagues, TRAViz wants to say "Thank You" to: Christin Richter, Anna Jänicke, Marco

TRAViz collation of the Genesis chapter from the various translations of the Bible. 
Figure 5

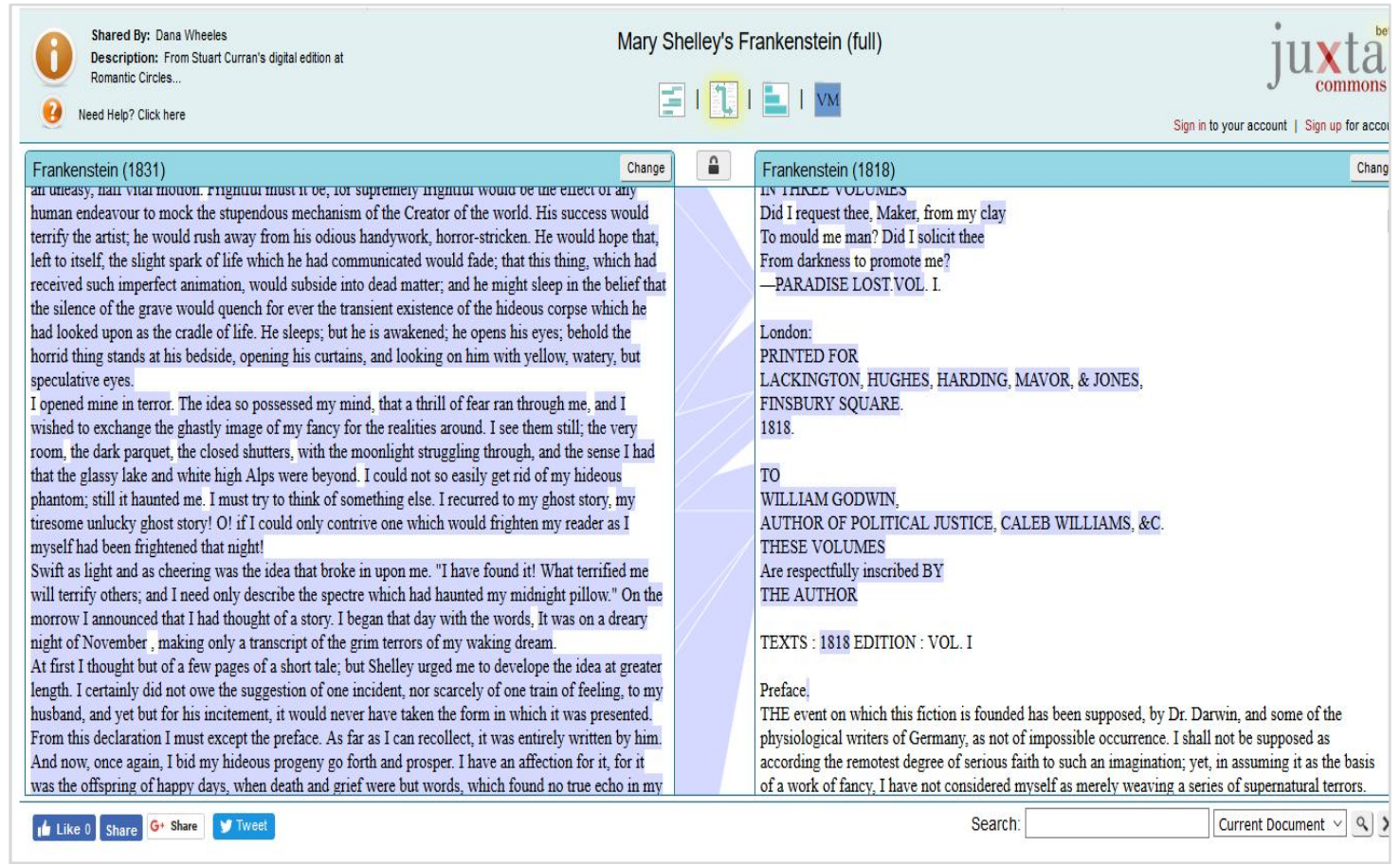

Juxta Commons, comparison of the 1831 and 1818 texts of Frankenstein

If 'a transmedia storytelling project employs interrelated texts from various forms (movie, video, website, etc.' (Kalogeras 27), then the above projects tell the story of various versions and forms of these texts - printed, oral, performative - from different times and contexts. The representation of such versions is itself a collated storyline and, when we read the above visuals, forces us to read, say, Frankenstein as an intertext. Graphic visualization is transmedial in that we read a phenomenon - the text - spread across different media, although brought to life on our screen. ${ }^{1}$

Then, as textual scholars, we in the Literary Studies field, take notes and visualize the data from the materials available in print form. This enables us to explore the material in certain ways. But the visualization seen in instances such as the above also enable to explore the material in new ways. Graphic visualization as a work of textual criticism and adaptation then may be seen contributing to new and emergent ways of understanding the material is best, for instance the very clear picture of intertexts when we read any text. That is, graphic visualization may be read as an instance of a specific kind of comparative textual production itself, one that instantiates not only intertextuality but also transmediality and adaptation.

As should be clear by now, I am addressing adaptation as a mode of cultural production in literary criticism rather than as a genre- or medium-specific text. We understand, almost as a truism, that any representation occurs in a medium, and that the characteristics of that medium dictate the key properties of the representation that occurs in that medium. If so, the representation of textual relations across texts in the form of graphic displays or big data charts and maps is itself a form of text that is facilitated by the digital world. It adopts the modes of display, the codes of representation made possible by software - as seen in the TRAViz maps above - to make a comment about the texts being examined. Graphic visualization is an adaptation of literary texts to the digital medium in order to better understand the former. This of course suggests implicitly that literary criticism in the age of the digital is also transmedial. 


\section{Literature, Graphic Visualization and Metareference}

Werner Wolf uses the term 'metareference' to describe the transmedia narrative's system of referencing.

[First, the term] 'reference' encompasses not only (symbolic) verbal signs but - with an eye to media such as painting or photography - signs of any kind (including iconic and indexical ones) ... 'reference' may also encompass complex and detailed symbolic relationships that support a specific discursive meaning, in particular a higher-level metacomment on elements situated at a lower object-level. Second, 'reference' as designating the relation between sign and referent must not be restricted to the world 'outside' the sign or sign system [heteroreference] but also apply to elements, or the entirety, of the sign (system) in question itself so that it will include self-reference [selfreference] (17)

As we have seen in the case of digital criticism and transmedia studies, the critical work of collation, tracking and lexicography invariably describes the process by which the study has been arrived at. The essays reference the software, sometimes even the algorithms, the choices made in terms of text-selection - the extra-semiotic reality - and the structural composition of the page of criticism itself. Thus the work of criticism in the digital age gestures at once to contexts and processes outside the task and textual frame, and to signs and symbols within it.

Metareference could be to the world at large or to a reference outside (heteroreference) or to something within the text (self-reference). In the case of the former, in transmedia texts such as the ones depicted above, the metareference is in fact to the reality of textual production, to the cultural and social history of the texts, now made visible in the graphic visualization of the same. However, by pointing to the very process of compiling this textual history - for instance by explaining the process of checking block texts, passages, line-by-line checking - the transmedia text laid out on Juxta Commons or Tessera embodies metareference. Note, in the Frankenstein texts the links to Share, to Like, the box for scrolling through the document. These are all metareferences.

What is important is to recognize that in transmedia metareferencing is a form of adaptation because it takes material from various media - print, manuscript, codexes - to compose the cultural history of the text in the form of whatever is laid out on the screen. The coding of metadata on the same screen is another instance of transmedia metareferencing that may be read as adaptation. For us, the readers, this enables us to move to the next, or meta, level beyond the text on screen. For instance, when we read the screen shot of Tessera's or TRAViz's unpacking of the similarity and variance across authors/texts, we become aware of the metadata such as date of publication, edition, translator, original source, etc. Werner Wolf writes: 'where metareference is properly understood, an at least minimal corresponding 'meta-awareness' is elicited in the recipient' (31).

In the age of digital reading, graphic visualization is a form of adaptation, of multiple texts and sources across media, embedding metareferencing so as to generate a meta-awareness.

That said, the process of digitizing, with metadata, texts from the canon or corpus is not a merely technological act. Jerome McGann notes that texts are sites of cultural memory, and they are material artifacts with their own sociohistorical affiliations and influences - traditionally studied by philologists who wished to track the evolution of a work. 
The historical record is composed of a vast set of specific material objects that have been created and passed along through an even more vast network of agents and agencies. The meanings of the record - the interpretation of those meanings - are a function of the operations taking place in that dynamic network. Only a sociology of the textual condition can offer an interpretive method adequate to the study of this field and its materials. (22)

In the hurry to digitize, this specific aspect is often lost, McGann argues. The accuracy of digitizing textual material is only the bare minimum of the process. McGann draws attention to the Critical Edition as a site where such historical processes in the making of texts are generally available, as a matter of principle. For digitization to respect this history, McGann argues, it must provide what the Critical Edition does: 'hyperlinks to the received sociohistorical network of materials with which the author's work is meshed and implicated' (25). Digitization runs the risk of losing what McGann terms 'bibliographical materiality' (26). McGann's is indeed a valid argument. Visualization of poetic influences and metareferencing do offer a measure of such contextualization of the literary-text-as-social-text. But with the overwhelming emphasis on drawing connections, some of the older philological practices may need to be revived if we are to acknowledge that literary texts represent, embody - materially - the progression of historical and cultural memory. For this, McGann suggests, literary scholars need to be involved closely with the digitization project itself, and assert the principles of historically rooted textual inquiry.

\section{Towards a Poetics of Transmedial Adaptation}

When many media forms are used to tell a story, or retell one, we have transmedial adaptation.

Figure 6

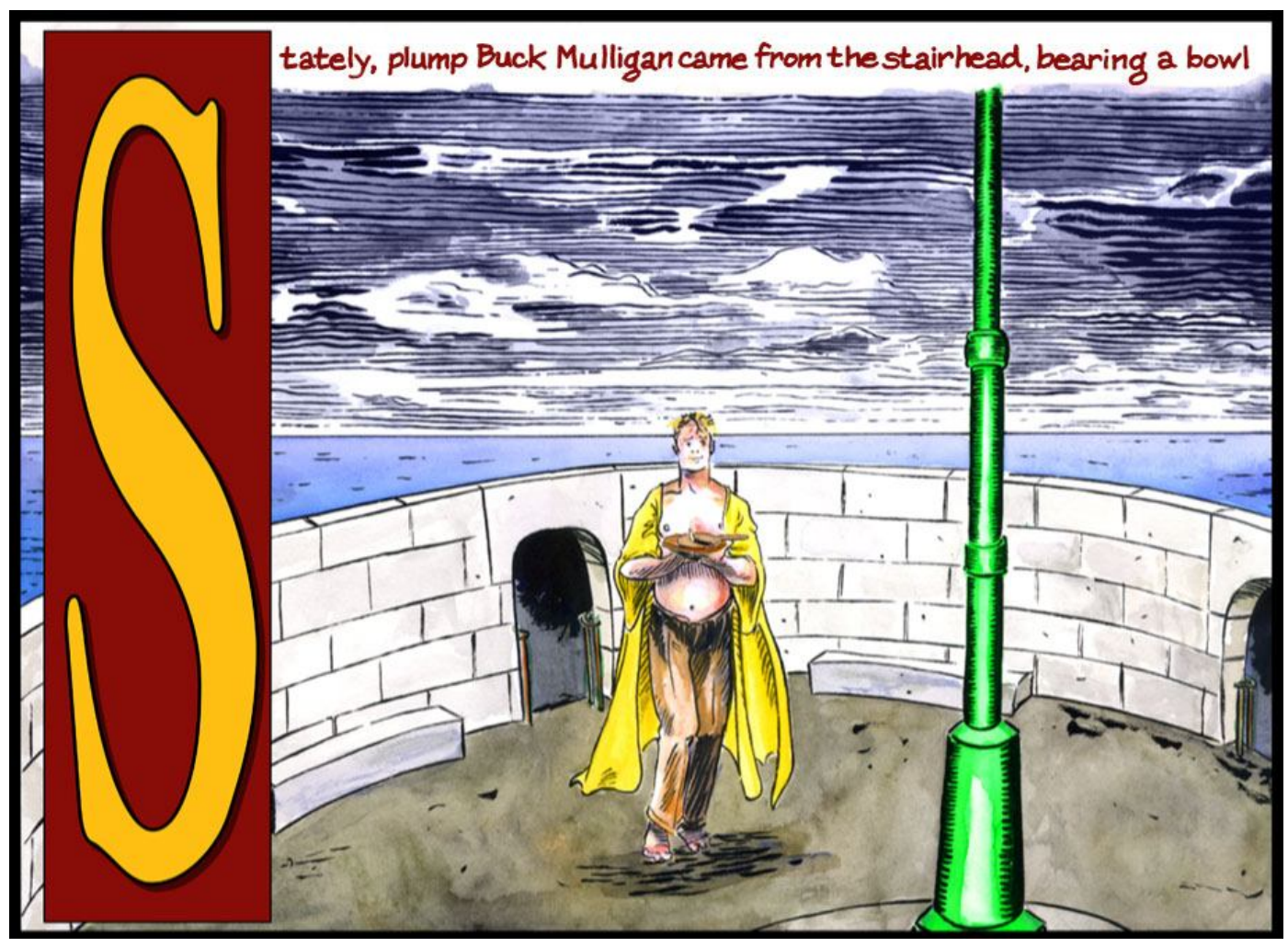




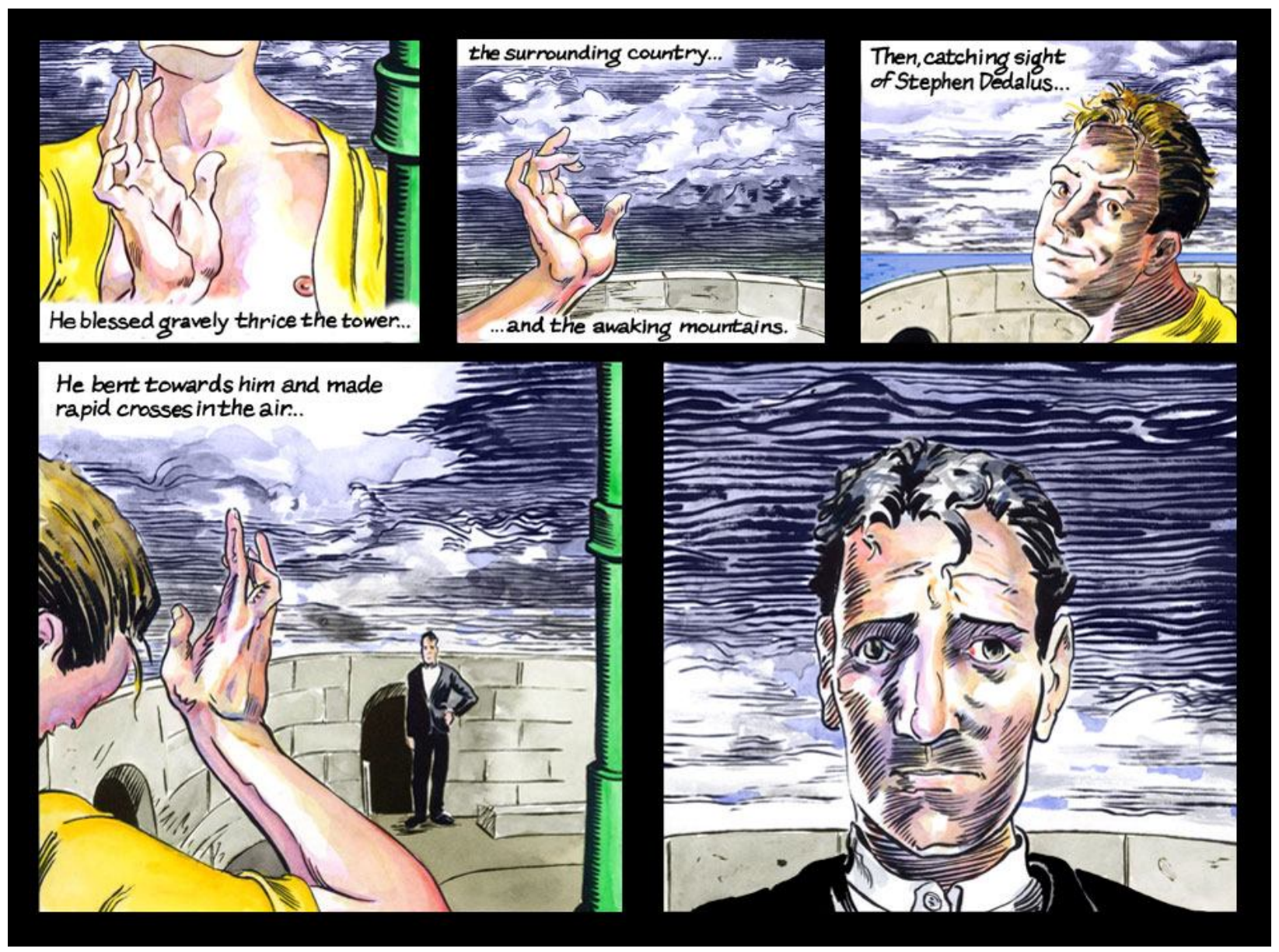

Ulysses Seen http://www.ulyssesseen.com/comic/us_comic_tel_iii.html

In what may be seen as a move towards mapping such a poetics, I forward the argument that the aesthetic of what is commonly called magical realism informs the transmedial poetics of adaptation. Magical realism is 'a mode of narration that naturalises or normalises the supernatural; that is to say, a mode in which real and fantastic, natural and supernatural, are coherently represented in a state of equivalence' (Warnes 3). The reader, as a result, is unsettled because $\mathrm{s} /$ he is unable to ascertain whether the events, action, characters being described are a part of the diegetic world of the story or a part of the imagination of a character's mind in this diegetic world. Causes of the events cannot be readily tracked, in the magical realist tradition, to empirically verifiable events: 'the horizons of the causal paradigm are extended to include events and possibilities that would ordinarily be circumscribed' (Warnes 12). Or,

[Magical realism may] critique the claims to truth and coherence of the modern, western world view by showing them up as culturally and historically contingent. The truth claims of causality are seen as contingent on consensus, founded in language, and driven by discourse about reality rather than reality itself. (13)

In the above representation, the first images we see of Buck Mulligan are from a vantage point outside the frame looking in at him. As the tale moves on, we see Mulligan turn to look at something: 'Then, catching sight of Stephen Dedalus...'. Thus far, Dedalus is not in the panel. In subsequent panels, we see Dedalus through the eyes of Mulligan, and perhaps the narrator outside the diegetic space of the panel. 
Paratextual materials also direct us to the way in which we must read the images and text. The 'Reader's Guide' to the project writes:

Rob's drawing gives us an intriguing birds-eye view that conveys at least two important pieces of information: $a$ ) we're out in the middle of nowhere, and b) Mulligan is putting on a show without an audience. Not having an audience is intolerable for Mulligan, so he will shortly summon Stephen Dedalus to serve as an altar boy to his perverse shaving mass. Making the "S" extra big, like Random House did when they designed the first American edition of Ulysses, Rob really makes it stand off the page ... (http://ulyssesseen.com/landing/2009/o4/telemachus-3/)

The above explanation is a protocol of reading. The 'pieces of information' is what we are directed to by the paratexts, in case we missed it in our first round of reading the page. This itself is an adaptive technology in operation: one reader's experience may have determined the design of the page(s), and therefore been adapted for future users. While not strictly personal in terms of adaptation of the literary text, the paratexts indicate a corelating - therefore, social - of such experiences. Once these have been pooled and strategies evolved, protocols can be developed addressing the most common issues of the reading experience and to enhance readability.

It is not clear how the narrator's vantage point merges with that of Mulligan's, if at all. There is no way, in other words, of separating in this visualization of the opening scenes of Ulysses, whether the first cognition of Dedalus is through the distanced narrator or Mulligan. When, critics observe, the real and the supernatural are merged in the magical realist, we understand how Ulysses Seen operates. Through whose eyes are we, the readers, seeing Dedalus? What and how is the equivalence between the framing narrative vantage point and that of the character Mulligan? Is Dedalus in the visual representation we see on the screen, the Dedalus in Mulligan's cognitiveimaginative frame?

As Christopher Warne's argument cited above proposes, the magical realist aesthetic in terms of transmedial adaptations underscores the point that the reality of a Dedalus is determined for us by the visual discourse (in the webcomic) of Mulligan and the beyond-the-panel narrator. How we see Dedalus is dependent on how these two sets of 'eyes' view Dedalus.

The second key point is: in the case of the annotated webcomic version, the paratexts complicate the reading of the Joyce text as well.

Figure 7

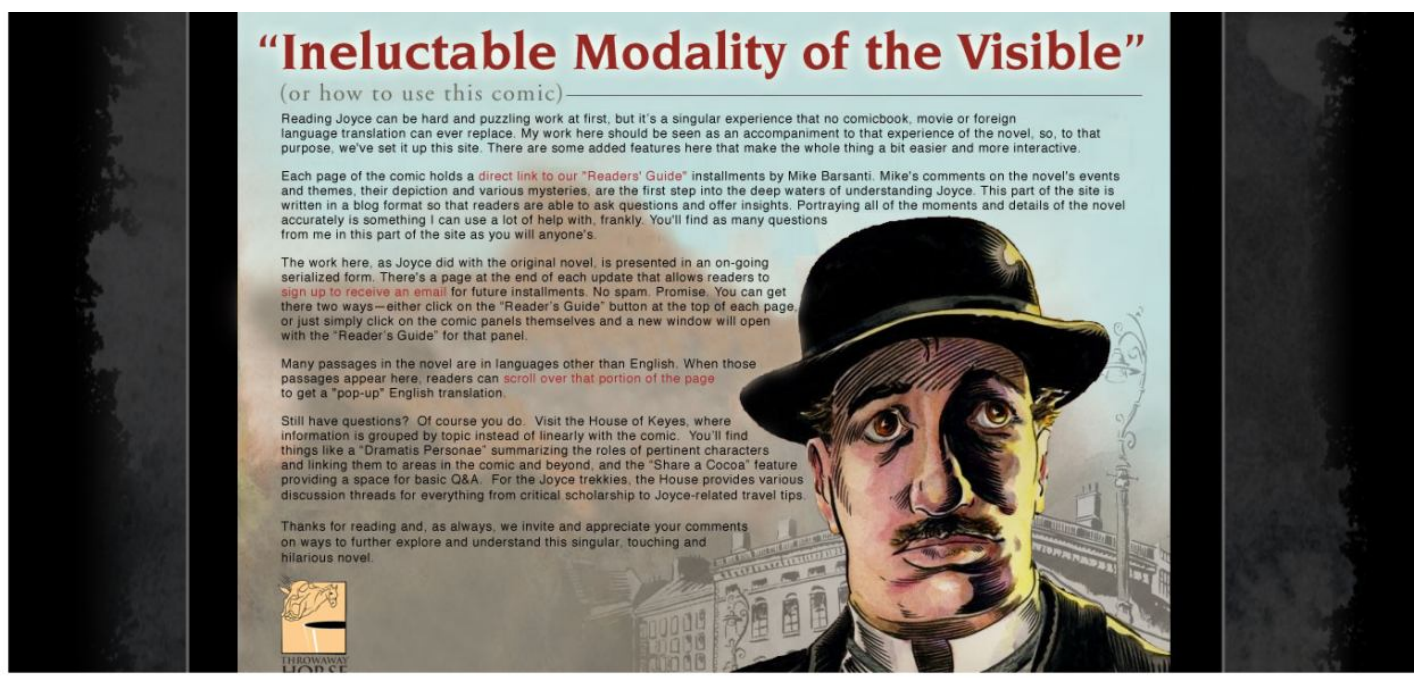



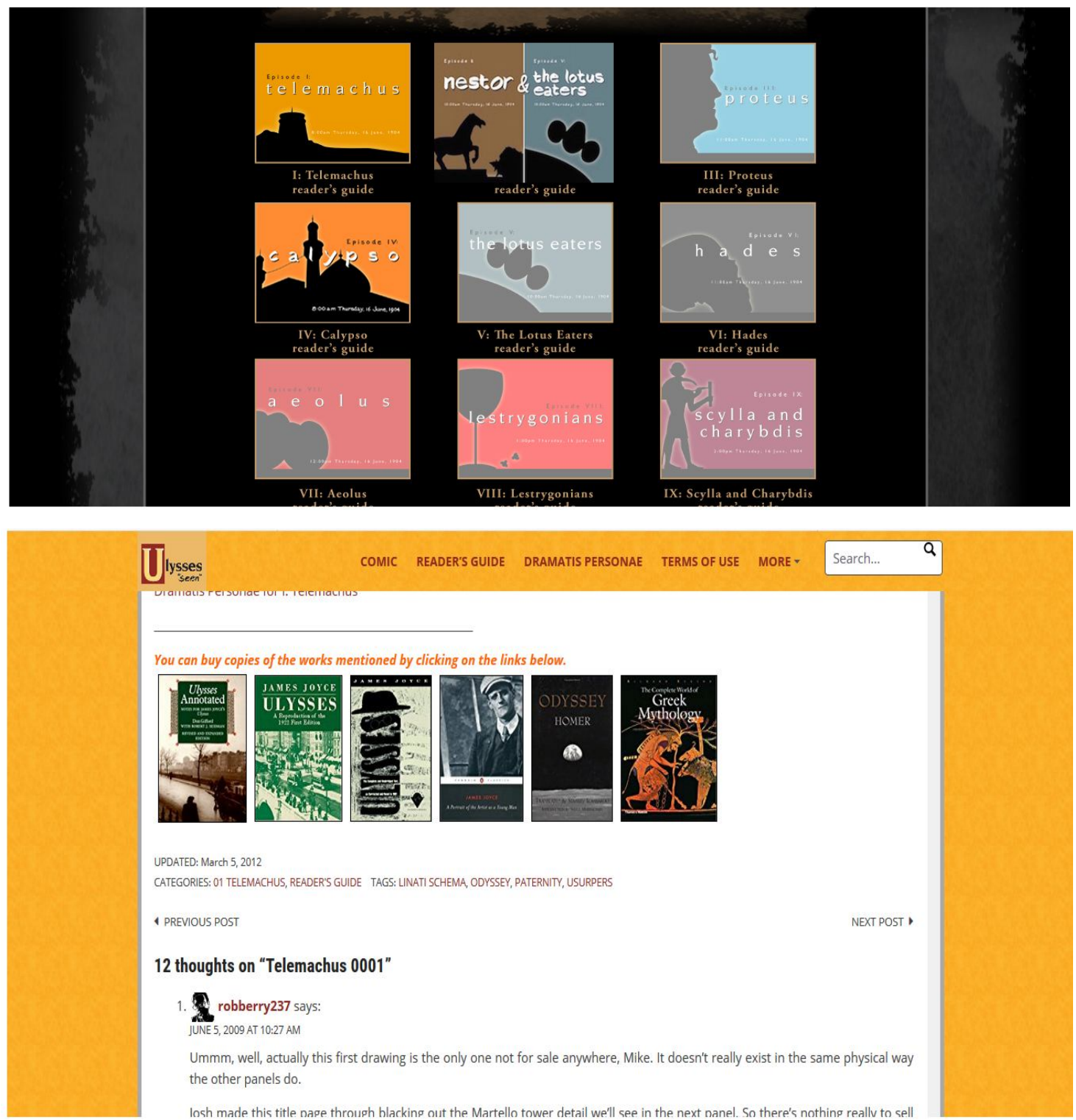

Paratexts for Ulysses Seen

We now know, from Ellen McCracken's work, that paratexts in electronic literature are key frames through which we read the texts. McCracken writes:

Before buying an e-book on Amazon, for example, readers may have encountered references to the book on blogs; seen other readers' comments and ratings posted on Amazon, other websites, or Twitter; viewed the author's web page on Amazon; or followed a link on Amazon to algorithmic recommendations based on browsing history and purchases. As part of a larger textual orbit, these new digital epitexts are intended to propel readers toward the central reading experience of the text itself along a centripetal vector, and from there, further inward. During or after the reading process on the portable device, however, this same paratextual material can also work centrifugally, interrupting or extending the story outward. During the reading process one can easily tap a tablet's 
touchscreen to view comments, ratings, reviews, and author information and commentary without putting the device aside. (2013: 111)

When and as we read the chapters, we are aware of the paratextual apparatus that frames this reading. Magical realism within the diegetic space of the webcomic Ulysses Seen that renders cognitive and epistemological recognition of the coherent, bounded text uncertain. The webcomic adaptation's incorporation of the Amazon page (with not just Ulysses but also other 'related' texts), bloggers' comments, illustrations 'make seen' what was never seen before: related texts, responses, visualization of Joyce's characters, among others.

Thus, the poetics of the webcomic adaptation destabilizes the way one reads a text like Ulysses, and this is quite fitting, since Joyce did want to make us work towards an interpretation.

\section{Acknowledgement}

An earlier draft of this essay was delivered as a Keynote address at a national conference on 'Reworking, Re-imagining, Re-inventing: The Changing Faces of Adaptation Studies', organized by the Dept. of English, St Andrews College, Mumbai, 17-18 November 2017. I am grateful to Samira Nadkarni and Susan Lobo for inviting me, Rukmini Pande for her comments and Michelle Philip for an enthusiastic response. Throwaway Horse has been contacted for permission to use images from Ulysses Seen, and responses awaited.

\section{Note}

${ }^{1}$ That said, Johanna Drucker's warning is a good one: 'the artifactual features of the graphic as if they are an unmediated presentation of underlying information' (239). Adaptation into the graphic form is a mediation of existing data, even when this data is a fictional universe of, say, a novel.

\section{References}

Abraham, Nicolas and Mária Török. The Wolf Man's Magic Word: A Cryptonymy. Minneapolis: U of Minnesota P, 1986.

Drucker, Johanna. 'Graphical Approaches to the Digital Humanities', in Susan Schreibman, Ray Siemens, and John Unsworth (eds) A New Companion to the Digital Humanities. Marsden, MA: Wiley-Blackwell, 2016. 238-250.

Graham, Elyse. 'Introduction: Data Visualisation and the Humanities', English Studies Online Publication 18 July 2017.

Jänicke, Stefan and David Joseph Wrisley. 'Visualizing Mouvance: Toward a Visual Analysis of Variant Medieval Text Traditions', Digital Scholarship in the Humanities 32.2 (2017): 106-123.

Kalogeras, Stavroula. Transmedia Storytelling and the New Era of Media Convergence in Higher Education. London: Palgrave-Macmillan, 2014.

McCracken, Ellen. 'Expanding Genette's Epitext/Peritext Model for Transitional Electronic Literature: Centrifugal and Centripetal Vectors on Kindles and iPads', Narrative 21.1 (2013): 105-124.

McGann, Jerome. A New Republic of Letters: Memory and Scholarship in the Age of Digital Reproduction. Cambridge, MA: Harvard UP, 2014. 
Pawlicka, Urszula. 'Data, Collaboration, Laboratory: Bringing Concepts from Science into Humanities Practice', English Studies 98.5 (2017): 526-541.

Sinclair, Stéfan and Geoffrey Rockwell. 'Text Analysis and Visualization: Making Meaning Count', in Susan Schreibman, Ray Siemens, and John Unsworth (eds) A New Companion to the Digital Humanities. Marsden, MA: Wiley-Blackwell, 2016. 274-290.

Pressman, Jessica. Digital Modernism: Making it New in New Media. Oxford: Oxford UP, 2014.

Thon, Jan-Noël. Transmedial Narratology and Contemporary Media Culture. Lincoln and London: U of Nebraska P, 2016.

Wolf, Werner. 'Metareference across Media: The Concept, its Transmedial Potentials and Problems, Main Forms and Functions', in Wolf, with Katharina Bantleon and Jeff Thoss (ed) Metareference across Media: Theory and Case Studies. Amsterdam, New York: Rodopi. 1-88. 